\title{
European harmonised system for training and qualification of adhesive bonding personnel
}

\author{
Luísa Quintino ${ }^{1,3^{*}}$, Italo Fernandes ${ }^{2,3}$ and Eurico Assunção $0^{3,4}$
}

\footnotetext{
* Correspondence: lquintino@ist.utl.pt ${ }^{1}$ Instituto Superior Técnico, DEM, Av. Rovisco Pais, 1049-001, Lisboa, Portugal

${ }^{3}$ EWF-European Welding Federation, Av. Prof. Dr. Cavaco Silva, n. 33, Taguspark, Apartado 012,

P-2740-120, Porto Salvo, Portugal Full list of author information is available at the end of the article
}

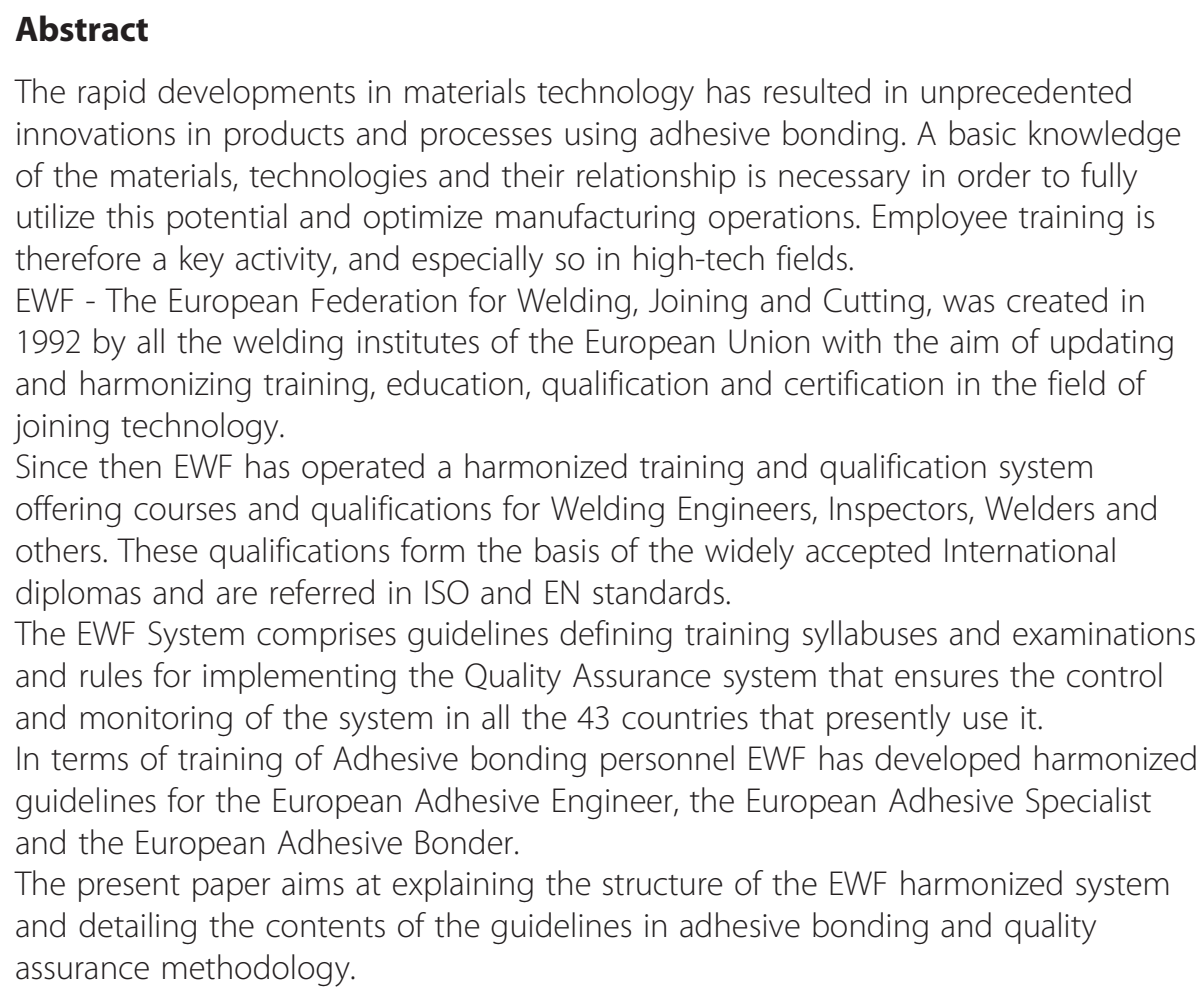

The rapid developments in materials technology has resulted in unprecedented innovations in products and processes using adhesive bonding. A basic knowledge of the materials, technologies and their relationship is necessary in order to fully utilize this potential and optimize manufacturing operations. Employee training is therefore a key activity, and especially so in high-tech fields.

EWF - The European Federation for Welding, Joining and Cutting, was created in 1992 by all the welding institutes of the European Union with the aim of updating and harmonizing training, education, qualification and certification in the field of joining technology.

Since then EWF has operated a harmonized training and qualification system offering courses and qualifications for Welding Engineers, Inspectors, Welders and others. These qualifications form the basis of the widely accepted International diplomas and are referred in ISO and EN standards.

The EWF System comprises guidelines defining training syllabuses and examinations and rules for implementing the Quality Assurance system that ensures the control and monitoring of the system in all the 43 countries that presently use it. In terms of training of Adhesive bonding personnel EWF has developed harmonized guidelines for the European Adhesive Engineer, the European Adhesive Specialist and the European Adhesive Bonder.

The present paper aims at explaining the structure of the EWF harmonized system and detailing the contents of the guidelines in adhesive bonding and quality assurance methodology.

Keywords: Qualification of personnel; Quality assurance; Adhesive bounding engineer; Adhesive bounding specialist; Adhesive bounder

\section{Springer}

\section{Background}

Innovation in manufacturing technologies has led to the development of adhesive bonding by allowing the use of newly developed materials that exhibited a variety of properties capable of fulfilling industry's continuously challenging goals, in using higher performing materials in joints presenting higher mechanical properties and durability $[1,2]$.

In the course of time adhesives have gained a stable position in an increasing number of production processes. There is hardly any product in our surroundings that does not contain at least one adhesive, from daily common products as labeled bottles to high demanding products as window frames in planes or automobiles $[3,4]$.

(c) 2013 Quintino et al.; licensee Springer. This is an open access article distributed under the terms of the Creative Commons Attribution License (http://creativecommons.org/licenses/by/2.0), which permits unrestricted use, distribution, and reproduction in any medium, provided the original work is properly cited. 
The rapid developments in materials technology has resulted in unprecedented innovations in products and processes using adhesive bonding. A basic knowledge of the materials, technologies and their relationships is necessary in order to fully utilize this potential and optimize manufacturing operations.

This technological development is proceeding at an ever faster pace, making continuous training and follow-up training absolutely vital. Only qualified employees, whose knowledge is continuously kept up to date, can organize, evaluate, correlate and utilize information. This is a prerequisite for optimum commercial returns. Employee training is therefore a key activity, and especially so in high-tech fields.

The European Federation for Welding, Joining and Cutting (EWF) is an organization in which international expertise in joining and related technologies is assembled. For nearly 30 years, these organizations have been developing guidance documents and technology exchange mechanisms to support companies seeking to adopt best practice in joining. This has been a monumental effort, culminating in the installation of unique and comprehensive training, qualification and certification systems, applied to both people and companies, harmonized on a world-wide basis [5].

This paper gives details of the EWF systems that have been developed and what has been achieved as a result of them. It also outlines the challenges ahead for EWF and how they are being addressed.

\section{Methodology for Designing the Harmonized European training and qualification for adhesive bonding personnel}

The EWF (European Welding Federation) work on the development of harmonised courses which started in 1980, resulted in the implementation of a series of training and qualification guidelines and in the definition of examination criteria for welding personnel [6].

The existing Guidelines define the course syllabus, defining for each subject objectives, scope and expected results, including the minimum teaching duration in hours assigned to them.

Access to the harmonised courses is allowed only to those who possess an appropriate general education, equivalent but different for each country as these are based on national education systems.

Figure 1 represents the structure of the international professional Qualification System of Welding Personnel managed by EWF. It can be seen that an extensive range of joining and joining related courses and qualifications available. These courses are valuable to manufacturers seeking to ensure that all their staff with welding tasks and responsibilities are properly trained and meet the requirements of industry.

The training ends with a theoretical and practical exam held by an independent examination board. On successfully passing the exam, the trainee receives a diploma which is recognized throughout Europe and by the EWF (European Federation for Welding, Joining and Cutting).

The use of the EWF system has grown since it started being offered, for welding professionals in 1992. Till the present more than 200000 diplomas have been awarded and the EWF guidelines are referred in several standards, namely in the field of welding technology.

The Adhesive Bonding guidelines seek to achieve harmonization and a common standard in the examination and qualification of professional adhesive professionals in Europe [7]. The national welding and joining organizations, being member of the EWF, mutually 


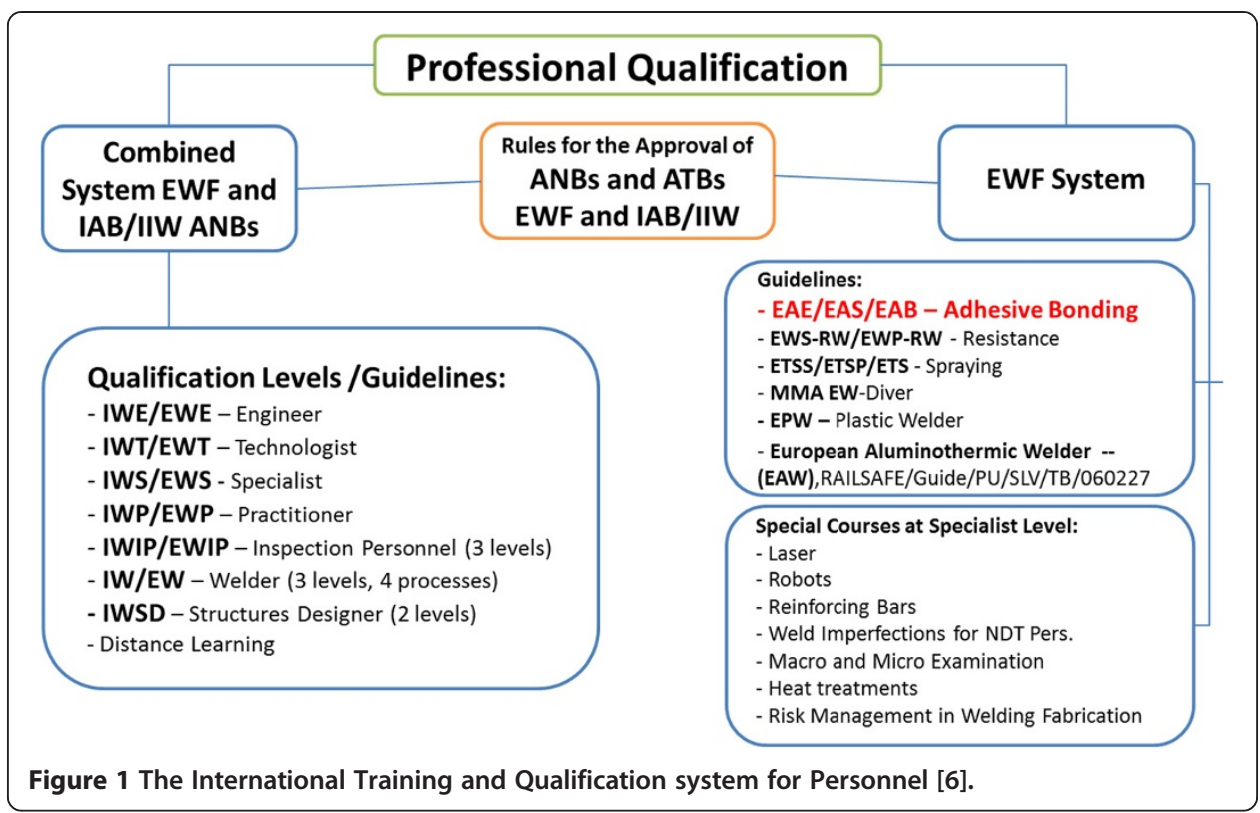

acknowledge the Diploma awarded in any Member State to European Adhesive Engineer, Specialist, Bonder, following examination conducted in accordance with these Guidelines.

\section{Results and Discussion - Course Structure and Quality Assurance System}

\section{European adhesive Engineer}

The adhesive engineer is responsible for the integration of adhesive bonding into the design and manufacture of products, including design, evaluation of process parameters, problem solving and failure analysis.

The EWF guideline for the European harmonized course [7] proposes the following for the theoretical education topics and minimum hours allocated to them, Table 1 Theoretical Educational Teaching Hours for the European Adhesive Engineer.

It has been agreed, by the EWF members, that entry to such a programmed should be on the basis of an engineer having received prior education training to a postgraduate level. Participates should have a primary degree in an engineering or related discipline

Table 1 Theoretical educational teaching hours for the European adhesive Engineer

\begin{tabular}{lc}
\hline Theoretical education & Hours \\
\hline 1. Adhesion and adhesives & 48 \\
2. Materials as adherents & 40 \\
3. Construction and design & 40 \\
4. Durability & 24 \\
5. The Bonding process & 35 \\
6. Testing and analysis & 36 \\
7. Health and safety & 8 \\
8. Qualification Management & 29 \\
9. Manufacturing Case Studies & 24 \\
10. Practical Skills Training & 40 \\
11. Examination & 8 \\
TOTAL & 332 \\
\hline
\end{tabular}


Table 2 Theoretical educational teaching hours for the European adhesive specialist

\begin{tabular}{lc}
\hline Theoretical education & Hours \\
\hline 1. Adhesion and adhesives & 14 \\
2. Materials as adherents & 14 \\
3. Construction and design & 12 \\
4. Durability & 8 \\
5. The Bonding process & 11 \\
6. Testing and analysis & 12 \\
7. Health and safety & 4 \\
8. Qualification Management & 7 \\
9. Manufacturing Case Studies & 8 \\
10. Practical Skills Training & 22 \\
11. Examination & 8 \\
TOTAL & $\mathbf{1 2 0}$ \\
\hline
\end{tabular}

recognized by the national government and assessed by the ANB - Authorized National Body. Therefore, it would be expected that participants should have at least a BSc degree. Definitions for each country are given in a directory of access conditions proposed by all of the 31 countries using the EWF System.

\section{European adhesive specialist}

The role of the specialist is to write and explain working instructions for the bonder in theory and practice. He will instruct and supervise practitioners. He will control process parameters, with responsibility for inspection and identification of problems.

The EWF course contents are given in Table 2 - Theoretical Educational Teaching Hours for the European Adhesive Specialist.

It is not obligatory to follow exactly the order of the topics given in this guideline and choice in the arrangement of the syllabus is permitted. The depth to which each topic is dealt with is indicated by the number of hours allocated to it in the guideline. This will be reflected in the scope and depth of the examination.

For entry to the programme 3 routes are available, Figure 2.

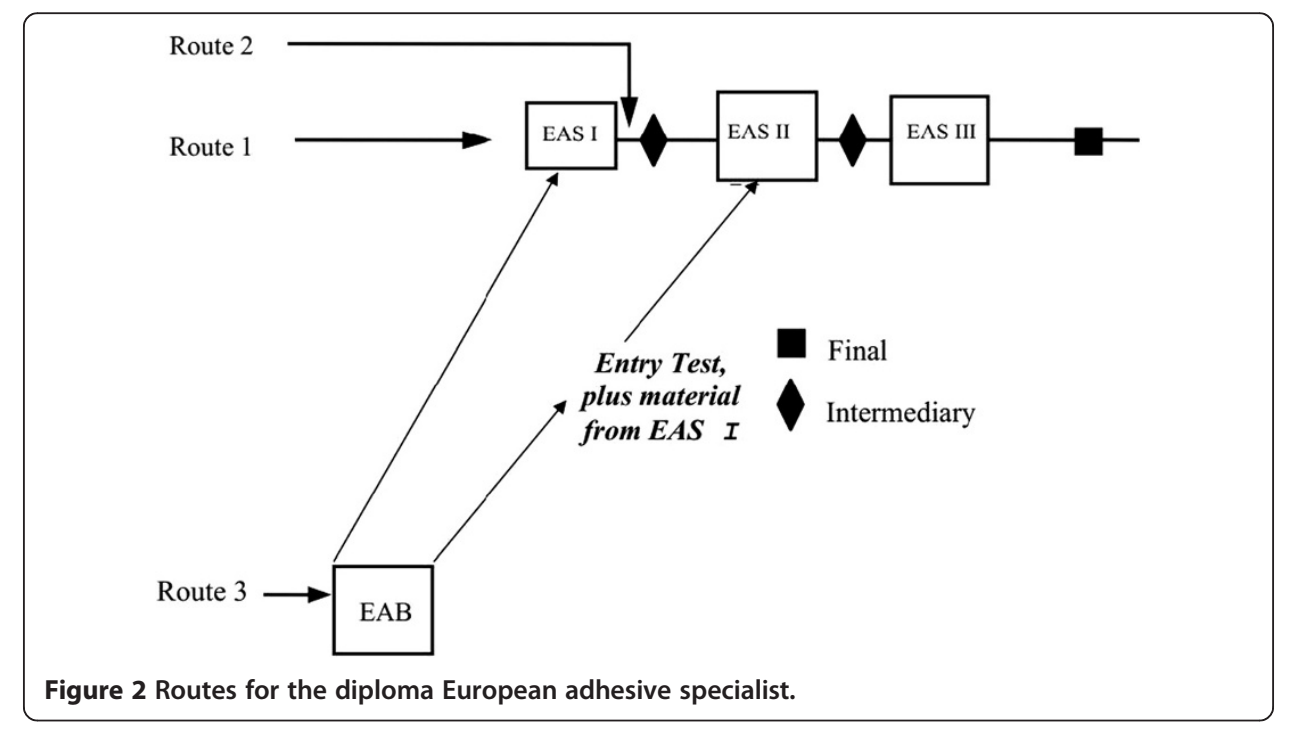


The minimum requirements for access to the module EAS - European Adhesive Specialist part I, by Route 1 and 2 are a specific technical qualification, decided by each European country in line with their national education system and a minimum age of 20 years including 2 years of job related experience.

In case of cooperation arrangements eg. with technical colleges, according to which basic parts of the course EAS part I are given under careful control of the ANB, before the participant complies with the access conditions, the access may be according to the route 2 indicated in the graph.

For Route 3 the minimum requirement for access to the module EAS part 0 are:

- EAB qualification

or

- qualification of a professional worker (with certificate after examination) in material processing profession and a minimum of three years experience in adhesive related activities, and a minimum age of 22 years.

Students who enter from the Bonder or professional worker (Route 3) must pass an entry test. Those who feel they lack the necessary basic technical education may take the preparatory EAS part 0 course before the test. If a student fails in the entry test he must take the full EAS part 0 course before the next test.

The rules for the conduct of the final examination by the ANB are prescribed under Examination and Qualification in this guideline. There is an mandatory intermediate examination and it is the responsibility of the training school to ensure that all participants have achieved the required knowledge. Failure in the intermediate examination will require the student to repeat the examination.

\section{European adhesive bonder}

A European Adhesive Bonder has industrial experience and can carry out bonding without supervision. He is able to read and understand working instructions and is well informed about production methods concerning bonded products

The contents of the EWF guideline for training are given in Table 3 - Theoretical Educational Teaching Hours for the Adhesive Bonder.

Table 3 Theoretical educational teaching hours for the adhesive bonder

\begin{tabular}{lc}
\hline Theoretical education & Hours \\
\hline 1. Fundamentals of Adhesion and Adhesives & 1 \\
2. Surface Preparation Before Adhesive Bonding & 4 \\
3. The Main Families of Adhesives and Sealants & 3 \\
4. Design and Construction of Adhesive Joints & 1 \\
5. Quality Control of Bonded Structures & 3 \\
6. Durability of Adhesively Bonded Joints & 1 \\
7. Benefits and Limitation of Adhesive Bonding Technology & 2 \\
8. Health and Safety & 1 \\
9. Practical & 18 \\
10. Examination & 6 \\
TOTAL & $\mathbf{4 0}$ \\
\hline
\end{tabular}


Table 4 Surface pretreatment of substrates

\begin{tabular}{|c|c|c|c|c|c|c|}
\hline \multicolumn{7}{|c|}{ Test Pieces for the practical exercises } \\
\hline No. & & & Type of joint & Surface preparation & Adhesives & Remarks \\
\hline & Hours & Total hours & & & & \\
\hline \multirow[t]{4}{*}{1} & 3 & 3 & Lap joint & $\begin{array}{l}\text { Degrease, grit } \\
\text { blast, degrease }\end{array}$ & & \multirow{4}{*}{$\begin{array}{l}\text { A representative cross } \\
\text { section of joint types, } \\
\text { surface preparation } \\
\text { in conjunction with } \\
\text { an appropriate adhesive } \\
\text { shall be used to assess } \\
\text { the candidate }\end{array}$} \\
\hline & & & & Anodise & 2 Part Cold Cure & \\
\hline & & & & Primers & & \\
\hline & & & & Chemical Treatments & & \\
\hline 2 & 1 & 4 & Double Strap Joint & & & \\
\hline 3 & 1 & 5 & Angle Lap Joint & & & \\
\hline 4 & 1 & 6 & Examination & & & \\
\hline
\end{tabular}

The practical training is structured in sets of exercises which are summarized in Tables 4 (Surface pretreatment of substrates), 5 (The use of different adhesive systems) and 6 (Quality control of Joints/Testing).

The access conditions for the adhesive bonder are not specified in a country by country basis as for the other levels, since all trainees with a the basic national education can enter this course.

\section{The quality assurance system}

An organisation, recognised by the EWF national member society, is appointed as the ANB for the supervision of the system for training, qualification and certification of personnel in each country. Representatives from these ANBs form the operational management and they nominate and approve Lead Assessors and Peer Assessors who ensure conformity of each ANB to agreed Rules [5].

ANBs are responsible at the national level for:

i. The assessment and monitoring of Approved Training Bodies (ATBs).

ii. The conduct of examinations.

iii. The assessment of applicants for qualification.

iv. The issue of Diplomas.

Table $\mathbf{5}$ The use of different adhesive systems

\begin{tabular}{|c|c|c|c|c|c|c|}
\hline \multicolumn{7}{|c|}{ Test pieces for the practical exercises } \\
\hline \multirow[t]{2}{*}{ No. } & & & Type of joint & Surface preparation & Adhesives & Remarks \\
\hline & Hours & Total hours & & \multirow{7}{*}{$\begin{array}{l}\text { Degrease, grit blast, } \\
\text { degrease }\end{array}$} & & $\begin{array}{l}\text { A representative cross } \\
\text { section of joint types, } \\
\text { adhesive systems } \\
\text { (including dispensing } \\
\text { techniques) shall be } \\
\text { used to assess the } \\
\text { candidate. }\end{array}$ \\
\hline \multirow[t]{6}{*}{1} & 2 & 2 & Lap joint & & Epoxy & \multirow{6}{*}{$\begin{array}{l}\text { A representative cross } \\
\text { section of joint types, } \\
\text { adhesive systems } \\
\text { (including dispensing } \\
\text { techniques) shall be } \\
\text { used to assess the } \\
\text { candidate. }\end{array}$} \\
\hline & & & & & Acrylic & \\
\hline & & & & & Anaerobic & \\
\hline & & & & & Cyanoacrylate & \\
\hline & & & & & Polyurethane & \\
\hline & & & & & 2 Part Cold Cure & \\
\hline 2 & 2 & 4 & Peel Specimen & & & \\
\hline 3 & 1 & 5 & Pin and Collar & & & \\
\hline 4 & 1 & 6 & Examination & & & \\
\hline
\end{tabular}


Table 6 Quality control of joints/testing

\begin{tabular}{lllll}
\hline \multicolumn{2}{l}{ Test pieces for practical exercises } & & Remarks \\
\hline No & \multicolumn{5}{l}{ Tours } & Total hours & Test & Joints to meet consistent values \\
1 & 2 & 2 & Adherend Prior to Bonding & \\
2 & 1 & 3 & Adhesive (Reception \& Storage) & \\
3 & 1 & 4 & Cured adhesive & \\
4 & 1 & 5 & NDT & \\
5 & 1 & 6 & Examination & \\
\hline
\end{tabular}

The ATBs (Authorised Training Bodies) are the organisations responsible for offering the courses in the market place.

ATBs are approved by the ANB, after applying for a certain scope of training, the ANB will assess the ATB to verify if the ATB complies with: training program against the EWF guideline, competence of the teachers, facilities for theoretical and practical training, students handouts and teacher visual aids, reference library in terms of books, standards, specifications and specimens.

There are now 31 countries that have joined this system with an Authorised National Body, as follows:

Austria, Belgium, Bulgaria, Bosnia Herzegovina, Croatia, Czech Republic, Denmark, Finland, France, Germany, Greece, Hungary, Iran, Italy, Netherlands, Norway, Poland, Portugal, Romania, Russia, Serbia, Slovakia, Slovenia, Spain, Sweden, Switzerland, Turkey, Ukraine United Kingdom.

EWF has started the harmonisation of traing and qualification for welding professionals in1992 and has a cooperation agreement with IIW for offering these courses in countries outside Europe. The harmonised courses in welding technlogy, are now offered around the world through IIW-IAB. There are more than 600 Authorised Training Bodies approved and supervised by the ANBs for implementing the EWF Qualification courses, which combine both underpinning knowledge and application experience, thereby providing close links with industrial practice.

The Adhesive Bonding System has been developed more recently by EWF and so far the countries with ANBs which include qualification of Adhesive Bonding personnel in their scope are: Austria, Belgium, France, Germany, Italy, Netherlands and Spain.

After the main education, special courses for additional learning are offered in many special areas, thus providing a specific education still closer to the job function.

EWF has started to harmonise the qualifications for welding professionals back in 1992 and its acceptance by all stakeholders is now clear. The increasing number of countries using the System in Europe and outside Europe is a sign of its increasing impact.

The Adhesive Bonding personnel system is more recent and is growing at a good pace in Europe. The EWF members are currently seeking for agreements with organizations interested in training these professionals and in many countries these organizations will become Authorised National Bodies for Adhesives and create their own structure for running the courses and respective qualifications in their countries. Another, more common, option has been to recognize schools and training organizations as Authorized Training Bodies for Adhesive Bounding. 
To companies that make products where joining technologies are used it is recommended to:

i) Consider the global market place.

ii) Get people trained, qualified and certified for maximum competence and recognition. For a company using joining of metals/plastics the way to assure the quality of the work is by training, qualifying and certifying its personnel through the EWF/IIW System. For a worker who wants to acquire skills and to achieve excellence in his profession the recommended goal is to achieve the appropriate EWF/IIW diploma.

iii) Demonstrate company capability to comply with EN and ISO standards by employing personnel with EWF/IIW certification.

By attending to the above points companies will benefit from improved competitiveness in the global market place and from an increased likelihood of trouble-free production and service performance of their products.

\section{Conclusions}

Welding and joining technologies are key to a significant proportion of Europe's manufacturing output thus the qualification of personnel is it major relevance.

The adhesive bonding courses offered by EWF members for Engineers, Specialists and Bonders include theoretical training which is supported by practical work in the laboratory to make things comprehensible.

The trainees thus get a deep insight into the world of adhesive bonding and on completion of training are in a position to e.g. monitor adhesive bonding in production, design joints which are suitable for adhesive bonding, select a suitable, certified adhesive, systematically detect faults in the process.

The system is under continuous improvements which include the design of more flexible courses, structured in modules with new paths, based on skills demonstration through exams and practical tests. Work is also going on regarding the introduction of more distance training modules.

\section{Competing interests}

The authors declare that they have no competing interests.

\section{Authors' contributions}

LQ wrote the paper and developed the methodology and was involved in the discussion of results. IF and EA contributed to the results and respective analysis and reviewed the paper. All authors read and approved the final manuscript.

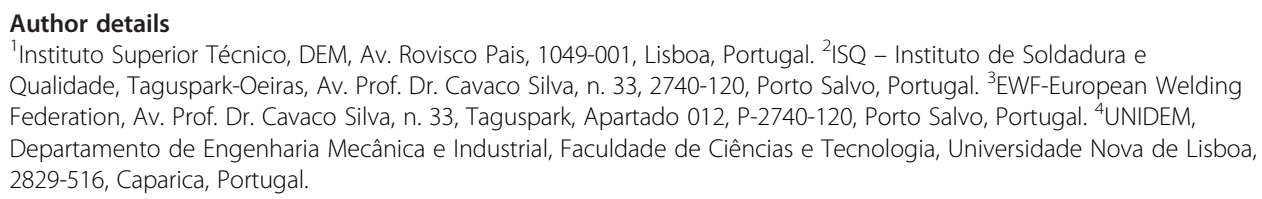


2. Thevenet $D$, Creac'hcadec R, Sohier $L$, et al. (2013) Experimental analysis of the behavior of adhesively bonded joints under tensile/compression-shear cyclic loadings. Int J Adh Adhes. 44:15

3. da Silva LFM, Magalhães AG (2007) Juntas adesivas estruturais, Publindustria, Portugal

4. Spaggiari A, Dragoni E (2013) Effect of mechanical surface treatment on the static strength of adhesive Lap joints. J Adhes. 89(9):677. DOI: 10.1080/00218464.2012.751526

5. Quintino L, Fernandes I, Miranda RM (2011) International harmonization of training and qualification in the manufacturing industry. J Eur Ind Train. 35(5):502

6. Quintino L, Ferraz R, Fernandes I (2008) International education qualification and certification systems in welding. Welding World. 52:1

7. (1998) Minimum Requirements for the Education, Examination and Qualification for Adhesive Bonder (EAB), Specialists (EAS) and Engineer (EAE), EWF. www.ewf.be

doi:10.1186/2196-4351-1-2

Cite this article as: Quintino et al:: European harmonised system for training and qualification of adhesive bonding personnel. Applied Adhesion Science 2013 1:2.

Submit your manuscript to a SpringerOpen ${ }^{\odot}$ journal and benefit from:

- Convenient online submission

- Rigorous peer review

- Immediate publication on acceptance

- Open access: articles freely available online

- High visibility within the field

- Retaining the copyright to your article

Submit your next manuscript at $\boldsymbol{\nabla}$ springeropen.com 